\title{
Disciplinary variations in academic promotional writing: the case of statements of purpose
}

Sibo Chen(D)

Correspondence: siboc@sfu.ca School of Communication, Simon

Fraser University, Burnaby, Canada

\begin{abstract}
This paper explores disciplinary variations in academic promotional writing via a comparative analysis of statements of purpose (SoPs) written for different disciplines. A total of 100 SoPs written by English as an additional language (EAL) applicants from mainland China were collected, which were drawn from five academic disciplines: business, engineering, humanities, science and social science. Following a corpus-driven research design, these SoP samples were analyzed in terms of their lexico-grammatical and rhetorical features. The data analysis suggests that although on the surface these SoP samples share similarities in lexico-grammatical and rhetorical features, they are quite different in terms of their preferred persuasion strategies. While SoPs written for engineering and science primarily base their self-promotional arguments upon the applicants' previous research experiences and future research prospects, those written for business, humanities and social science tend to focus on how the applicants' unique Chinese socio-cultural backgrounds would contribute to their desired programs. The above finding sheds light upon how academic genres are invariably embedded in disciplinary practices, with each discipline having its own communicative purposes, discourse community members, academic expectations and disciplinary constraints.
\end{abstract}

Keywords: Statement of purpose, Personal statement, Self-promotion, Academic genre, Disciplinary variation

\section{Introduction}

Statements of purpose (SoPs), also known as personal statements, are self-narrative essays required by the graduate application processes of most universities in the West. The SoP is arguably the most significant piece of writing during the transition between undergraduate and graduate studies since it is often the only discursive space among the required graduate application documents that is fully controlled by the applicant. Nevertheless, the SoP remarkably differs from other academic genres mainly produced by undergraduate writers: it tends to be a fairly short, personal and open-ended text with considerable disciplinary variations (Chiu, 2015, 2016; Samraj \& Monk, 2008). Even within the same discipline, different graduate programs may vary in criteria for evaluating submitted SoPs. Such program-specific information is often opaque, which, combined with the fact that authentic samples of successful SoPs are not readily accessible to prospective SoP writers, makes the SoP a "semi-occluded" genre

(C) The Author(s). 2017 Open Access This article is distributed under the terms of the Creative Commons Attribution 4.0 International License (http://creativecommons.org/licenses/by/4.0/), which permits unrestricted use, distribution, and reproduction in any medium, provided you give appropriate credit to the original author(s) and the source, provide a link to the Creative Commons license, and indicate if changes were made. 
(Samraj \& Monk, 2008; Swales, 1996). Consequently, many graduate applicants consider SoP writing as an exceedingly daunting task and this challenge has been further intensified by the lack of institutional support for SoP writing at many universities (Dubb, 2011).

Although a few studies have explored the SoP's textual and rhetorical features and evaluative norms (Brown 2004; Chiu, 2015, 2016; Ding, 2007; Dubb, 2011; Samraj \& Monk, 2008), to date a thorough examination of disciplinary variations in SoP writing remains missing nor have findings been based on corpus-driven analysis. This paper thus aims to contribute to the ongoing discussion on the SoP genre via an exploratory corpus-driven study of the genre's potential disciplinary variations. The broader theoretical and pedagogical concerns of the study lie in the growing prevalence of promotional genres in academic writing and their potential pedagogical values for English as an additional language (EAL) writing instruction.

The remaining sections of this paper are organized as follows. Section 2 presents a brief sketch of previous research on the SoP genre, especially in terms of its unique genre features and potential disciplinary variations. Section 3 proceeds to the present study's data and research methods, followed by the report of the data analysis results in Section 4. Sections 5 concludes the paper by discussing the study's theoretical and pedagogical implications, especially the SoP genre's pedagogical potential for EAL writing instruction.

\section{Review of literature}

The concept of genre has been understood in a variety of ways in applied linguistics. Briefly speaking, the available definitions of genre have addressed it from three basic perspectives: textual regularity, social function and social context (Hyon, 1996). The perspective of textual regularity refers to the fact that texts belonging to the same genre can be recognized by their "shared structure, style, content and intended audience" (Swales, 1990, p.58). English for academic purposes (EAP) research, for instance, has paid special attention to structural move analysis to detect functional units regulating the global organizational patterns and content of different genres. The perspective of social function is mainly addressed by new rhetoric scholars' discussions of the relationship between text types and rhetorical situations (Coe, 2002) and Swales' (1990, 2004) conceptualization of "communicative purpose". This perspective suggests that genres are not merely collections of identifiable texts, but also textual schema we rely upon to create meanings that make sense to our intended audience. Finally, the perspective of social context describes the settings that different genres are situated in, with concepts such as "discourse community" (Swales, 1990, 2004) being proposed to depict the socio-rhetorical assemblages of people, who, gathered by shared occupational or recreational goals, develop different genres for within-group communications.

Viewing from a genre perspective, the SoP is a highly complex academic genre. Unlike other student genres with relatively rigid structures, few graduate programs offer detailed requirements for SoP writing, which, combined with the varying expectations held by different graduate programs' gatekeepers, creates enormous challenges for novice SoP writers (Chiu, 2015, 2016; Ding, 2007; Samraj \& Monk, 2008). These challenges have been further intensified by the lack of institutional support for SoP writing (Brown, 2004; Dubb, 2011). 
The SoP also differs from typical academic genres in its overt communicative purpose of self-promotion. Although promotional genres have been traditionally associated with texts produced in business settings (Bhatia, 1993). In recent years, researchers have increasingly recognized the "invasion" of promotional discourse into other discursive territories, including higher education. While on the surface the SoP resembles the cover letter genre in that both are produced for self-promotion, it should be noted that the SoP is not a genre used for within-group communications: SoPs are produced by graduate school applicants to gain access into their prospective discourse communities. Thus, the SoP writing process is also "a means of establishing a (credible) claim to a scholarly identity" (Hyland, 2012, p. 72) and many SoP writers have found such process extremely challenging (Chiu, 2016; Dubb, 2011).

Finally, the SoP is a "semi-occluded genre" characterized by a limited access to previous samples and an opaque evaluation process (Samraj \& Monk, 2008). Swales (1996) defines "occluded genre" as genres with limited/no open access to the public and this feature adds extra obstacles for prospective writers outside particular discourse communities. Although the SoP is absent from Swales' (1996) occluded genre list, it resembles other occluded genres in that accessing SoPs already submitted to graduate programs is generally restricted to admission committees due to privacy regulations and a considerable amount of graduate school applicants are unwilling to share their SoPs due to the personal details revealed in these texts. While there are numerous popular guidebooks for SoP writing, it has been found that the suggestions offered by these books are too general to effectively assist applicants who need specific suggestions for different academic disciplines (Samraj \& Monk, 2008). In short, the SoP is a complex undergraduate genre with occluded and self-promotional features, which partially accounts for the lack of relevant studies within the genre literature.

There have been two analytical focuses within the previous research on SoPs. The first analytical focus is the textual regulations of the SoP genre. Most of the previous studies on the SoP genre have adopted move-structural analysis to explore its prototypical rhetorical move structure. One common finding emerging from these studies is that the SoP genre involves four essential moves (introduction, relevant background, reasons for applying and conclusion) and one optional move (extra-curricular information or career goal) (Ding, 2007; Samraj \& Monk, 2008; Chiu, 2016). Meanwhile, the previous research also suggests noticeable disciplinary variations in terms of which move should be SoP writers' primary focus. The comparative analysis by Samraj and Monk (2008) found that while SoPs written for three disciplines (electronic engineering, linguistics and business administration) are identical in terms of their general rhetorical moves, they differ across disciplines in the associated steps: in their SoP corpus, SoPs written for electronic engineering paid much more attention to the "step of research focus" in contrast to their counterparts written for linguistics and business administration. Chiu (2016) further attributes such disciplinary variations to SoP writers' sense of writer positioning, target audience and the writing process.

The second analytical focus is the varying evaluative practices of SoPs across disciplines. Several studies on the SoP genre have tried to reduce its opaqueness through interviews with graduate admission committee members (Brown, 2004; Samraj \& Monk, 2008; Chiu, 2015). One contentious point emerging from the reported interviews is whether SoP writing should pay special attention to the construction of a 
"personal-self". While some disciplines such as psychology and electronic engineering tend to prefer a scientific epistemology by discouraging excessive personal details, this norm is not necessarily shared by disciplines oriented toward a humanistic epistemology. Another contentious point is to what extent a SoP would determine an applicant's fate. Chiu (2015), through her interviews with 19 faculty members in education, found that the evaluative processes of SoPs are broadly associated with the epistemological assumptions and the bureaucratic admission procedures of specific discourse communities.

Although the previous studies have offered many interesting findings on the SoP genre, they are limited in two aspects. First, these studies have included relative small data sets, with each study only handling 20 to 35 SoP samples from few disciplines. Such inadequacy of data inevitably compromises the generalizability of their findings. SoPs written for natural and social science programs, for instance, have not been analyzed so far. Second, these studies have mainly focused on the SoP genre's macro features (e.g. functional move structures) whereas the micro features of the SoP genre have been largely neglected. Overall, the results of these recent studies indicate the need for a multi-perspective analysis of SoPs produced for a variety of disciplines.

\section{Data and research method}

The present study focused on the SoP genre's potential disciplinary variations in lexico-grammatical and rhetorical features by examining SoP samples written for five academic disciplines: humanities, business, engineering, social science and science. Overall, three research questions guided the study:

1. What are the prominent lexico-grammatical features in SoPs produced by EAL writers?

2. To what extent do SoPs produced by EAL writers follow the prototypical rhetorical move structure identified in previous research (i.e. Ding, 2007; Chiu, 2016; Samraj \& Monk, 2008)?

3. Is there any noticeable variation among EAL SoPs written for different disciplines, in terms of lexico-grammatical and rhetorical features?

Data used for the present study were SoP samples produced by EAL writers from mainland China. The exclusive focus on Chinese EAL writers was meant to downplay the influence of cultural norms since previous research (Chen \& Nassaji, 2015) showed that cultural norms can noticeably influence SoP writers' preferences of politeness strategies. The research participants were recruited from the Chinese online forum Gter (http://www.gter.net/). Gter is one of the largest online forums in China focusing on topics related to applying for oversea universities. With more than 1.5 million registered users and approximately 1500 daily posts, the forum is an ideal site for participant recruitment. To collect the SoP samples, a recruitment letter was posted in the site's sub-sections to invite current graduate school applicants to submit their SoPs for the present study. To ensure the quality of the collected SoP samples, all the participants were asked to report their IELTS or TEOFL scores and SoPs submitted by participants with IELTS scores below 6.5 or TEOFL scores below 80 were excluded from the actual data analysis. SoPs remarkably failing to follow the general length (500-1000 words) and content (a statement outlining personal background and reasons for apply) requirements of SoP writing were also excluded. A total of 182 SoP samples were 
initially collected and then 100 of them were eventually used to compile the five corpora, with $20 \mathrm{SoP}$ samples in each representing the five major academic disciplines. Following the Chinese education system's categorization of academic disciplines, SoP samples written for business, humanities and social science were grouped as the Arts Division while those written for engineering and science are grouped as the Science Division. The five SoP corpora consist of a total of 94,870 tokens (Table 1).

As mentioned earlier, the present study examined the collected SoP samples in terms of their lexico-grammatical and rhetorical features. For lexico-grammatical features, the SoP samples were analyzed via a corpus-driven method. The five corpora's lexicogrammatical features were examined through a two-step procedure. First, the lexical frequency list of each corpus was generated to identify the keywords of the SoP samples. Then, the concordance lines of identified keywords were extracted and analyzed for noticeable patterns. Both analyses were conducted by using the software AntConc (Anthony, 2011). For rhetorical features, the SoP samples were examined via a rhetorical move analysis. "Moves" refer to functional units within texts, which are constructed for identifiable communicative purposes and subsequently regulate a specific genre's expected content and rhetorical move structure (Swales, 2004). "Steps", by contrast, are components employed to realize a specific move. In the present study, functional moves and steps of each SoP sample were coded based on a modified coding scheme developed from previous research (Chiu, 2016; Ding, 2007; Samraj \& Monk, 2008). The purposes here were to further validate the quantitative findings and testify the prototypical rhetorical move structure of the SoP genre developed in previous research. I combined the coding schemes in previous research based on their commonalities and then test the modified coding scheme by coding the first 20 SoP samples in the collected data. Table 2 provides details of the finalized coding scheme. The identification of moves and steps was an iterative procedure involving carefully reading the SoP samples and making constant negotiations between the

Table 1 Disciplinary information and token sizes of SoP samples

\begin{tabular}{|c|c|c|}
\hline SoP (100 in total) & & Discipline and sample number \\
\hline \multirow[t]{3}{*}{ The Arts Division } & $\begin{array}{l}\text { Humanities } \\
(19,408 \text { tokens) }\end{array}$ & $\begin{array}{l}\text { Applied Linguistics (5), Arts Administration (1), Asian } \\
\text { Studies (8), Comparative Literature (1), Cultural Studies (2), } \\
\text { Translation (3). }\end{array}$ \\
\hline & $\begin{array}{l}\text { Business } \\
\text { (18,787 tokens) }\end{array}$ & $\begin{array}{l}\text { Accounting (3), Advertising (2), Corporate Communication (2), } \\
\text { Finance (3), Hotel Management (2), Management Studies (2), } \\
\text { Public Administration (3), Real Estate Management (3) }\end{array}$ \\
\hline & $\begin{array}{l}\text { Social Science } \\
\text { (19,847 tokens) }\end{array}$ & $\begin{array}{l}\text { Anthropology (2), Communication (3), Economics (2), } \\
\text { Environmental Policy (1), Journalism (2), New Media } \\
\text { Studies (1), Political Science (2), Psychology (2), } \\
\text { Public Health (1), Public Relation (1), Social Work (2), } \\
\text { Sociology (1) }\end{array}$ \\
\hline \multirow[t]{2}{*}{ The Science Division } & $\begin{array}{l}\text { Engineering } \\
\text { (18,384 tokens) }\end{array}$ & $\begin{array}{l}\text { Chemical Engineering (3), Civil Engineering (3), } \\
\text { Computer Engineering (3), Electronic Engineering (3), } \\
\text { Information Technology (1), Logistics (3), Manufacture } \\
\text { Engineering (2), Mechanic Engineering (2) }\end{array}$ \\
\hline & $\begin{array}{l}\text { Science } \\
\text { (18,444 tokens) }\end{array}$ & $\begin{array}{l}\text { Biology (4), Chemistry (3), Computer Science (4), } \\
\text { Environmental Studies (4), Material Science (2), } \\
\text { Physics (2), Plant Science (1) }\end{array}$ \\
\hline Total & \multicolumn{2}{|c|}{100 samples and 94,870 tokens } \\
\hline
\end{tabular}

Note: The "Arts Division versus Science Division" comes from the academic classification of the Chinese education system, which refers to non-scientific disciplines as "Wen-Ke" (Arts) and scientific disciplines "Li-Ke" (Science) 
Table 2 Moves and steps in the coded SoPs

\begin{tabular}{|c|c|}
\hline Moves & Descriptions \\
\hline Move 1: Introduction & $\begin{array}{l}\text { This move is primarily used by the applicant to get readers' } \\
\text { attention or to provide a brief introduction of the SoP's content. }\end{array}$ \\
\hline Step 1-A: Generalization/Attention catcher & $\begin{array}{l}\text { The applicant provides descriptions to catch readers' attention } \\
\text { or to claim the statement's aim. }\end{array}$ \\
\hline Step 1-B: Background & $\begin{array}{l}\text { The applicant states his/her education and personal background } \\
\text { information. }\end{array}$ \\
\hline Step 1-C: Goals or decisions to applying & $\begin{array}{l}\text { The applicant states his/her goal or decision to applying for } \\
\text { the target program. }\end{array}$ \\
\hline Move 2: Establishing credential & $\begin{array}{l}\text { This move reveals the applicant's relevant credentials for studying } \\
\text { and conducting research at the graduate level. }\end{array}$ \\
\hline Step 2-A: Education background & $\begin{array}{l}\text { The applicant reveals academic achievements related to the } \\
\text { proposed field of study. }\end{array}$ \\
\hline Step 2-B: Research experience & $\begin{array}{l}\text { The applicant addresses research experiences, research interests } \\
\text { or potential topics for graduate research. }\end{array}$ \\
\hline Step 2-C: Work experience & The applicant discusses professional experiences. \\
\hline Step 2-D: Personal attributes & $\begin{array}{l}\text { The applicant describes personal attributes that he/she believes } \\
\text { are appealing to the target program. }\end{array}$ \\
\hline Step 2-E: Other experience & $\begin{array}{l}\text { The applicant provides other personal information such as } \\
\text { language/cultural knowledge, volunteer experiences and } \\
\text { self-reflections. }\end{array}$ \\
\hline Move 3: Reasons for applying & $\begin{array}{l}\text { This move is used by the applicant to state reasons for pursuing } \\
\text { graduate study at the target program or institution. }\end{array}$ \\
\hline Step 3-A: Gap in applicant background & $\begin{array}{l}\text { The applicant discusses how his/her background can be improved } \\
\text { by pursuing graduate study at the target program or institution. }\end{array}$ \\
\hline Step 3-B: Positive gains & $\begin{array}{l}\text { The applicant describes the positive gains offered by the target } \\
\text { program or institution. }\end{array}$ \\
\hline Step 3-C: Program/university attributes & $\begin{array}{l}\text { The applicant describes the appeal of the target program or } \\
\text { institution. }\end{array}$ \\
\hline Step 3-D: Disciplinary and research reasons & $\begin{array}{l}\text { The applicant expresses his/her reasons for applying from the } \\
\text { research/discipline perspective. }\end{array}$ \\
\hline Move 4: Conclusion & $\begin{array}{l}\text { This move summarizes the SoP and makes a final appeal for } \\
\text { the admission committee's favorable consideration. }\end{array}$ \\
\hline Step 4-A: Goals/predictions of future & $\begin{array}{l}\text { The applicant states his/her future goals or career plan upon } \\
\text { the completion of the target program. }\end{array}$ \\
\hline Step 4-B: Self-evaluation & $\begin{array}{l}\text { The applicant re-states his/her relevant accomplishments for } \\
\text { self-promotion. }\end{array}$ \\
\hline Step 4-C: Final appeal & The applicant makes a final appeal to end the SoP. \\
\hline
\end{tabular}

coding scheme and text segments to determine the communicative purposes of functional units. The coding and analysis procedure was conducted via NVivo 10.

\section{Research findings}

\section{Lexico-grammatical features}

When calculated by raw frequency, most of top-ranking words in the five SoP corpora's word frequency lists are functional words such as articles, prepositions and conjunctions, which are typical of raw word frequency lists. To better explore the potential inter-corpus similarities and differences, new word frequency lists are generated by only retaining the content words of each corpus and the results reveal several noticeable patterns. As shown in Table 3, general academic words such as "study", "research" and "university" appear in each corpus' list, suggesting that the SoP writers are aware of it 
Table 3 Top ten most frequent content words in the SoP corpora

\begin{tabular}{|c|c|c|c|c|c|}
\hline & \multicolumn{3}{|l|}{ The Arts Division } & \multicolumn{2}{|c|}{ The Science Division } \\
\hline & Humanities & Business & Social Science & Engineering & Science \\
\hline 1 & Chinese (162) & social (67) & social (93) & research (105) & research (140) \\
\hline 2 & language (113) & knowledge (66) & China (92) & engineering (94) & study (80) \\
\hline 3 & culture (109) & university (64) & research (84) & university (86) & university (75) \\
\hline 4 & English (101) & study (63) & media (70) & knowledge (59) & engineering (61) \\
\hline 5 & teaching (75) & management (60) & communication (62) & study (58) & knowledge (61) \\
\hline 6 & university (68) & China (52) & study (61) & time (51) & project (56) \\
\hline 7 & China (66) & financial (51) & university (60) & design (48) & program (53) \\
\hline 8 & literature (65) & research (50) & work (59) & system (48) & science $(50)$ \\
\hline 9 & study (65) & program (48) & Chinese (54) & work (47) & computer (46) \\
\hline 10 & research (64) & work (48) & school (45) & project (46) & experience (39) \\
\hline
\end{tabular}

Note: numbers in brackets are the words' raw frequencies

being an academic genre. Each corpus' list also includes specific terms indicating its parent academic field. For instance, the humanities corpus's list contains words such as "language", "culture" and "literature" whereas words such as "management" and "finance" only appear in the business corpus' list. Another interesting result is the absence of the words "China" and "Chinese" from the two lists of the Science division, which implies that applicants in the Arts division are more likely to discuss their cultural and language backgrounds than those in the Science division. Finally, the word "research" ranks remarkably higher in the lists of the Science division than those of the Arts division, suggesting that more attention is paid to research achievements and prospects in SoPs written for the Science divisions than those for the Arts division.

As indicated by the lexical frequency analysis, SoPs written for the Arts and Science divisions may have different preferences when describing research and China-related experiences. To explore inter-corpus difference at the sentential level, the concordance lines of the lemmas "research" and "China"1 are examined in terms of their content focuses. Briefly speaking, the concordance lines of the lemma "research" can be divided into two categories: they focus on either the applicants' past experiences or their prospects. While the former primarily aim at establishing credentials or identifying gaps in background, the latter are mainly used to link the applicants to their target programs. As shown in Table 4, each corpus contains substantially more concordance lines describing the applicants' past experiences than those describing their prospects. In line with the lexical frequency analysis, the two corpora in the Science division contain much more research-related concordances than those in the Arts division.

Table 4 Number of concordance lines of the lemma "research" in the SoP corpora

\begin{tabular}{|c|c|c|c|c|c|c|}
\hline & \multicolumn{3}{|c|}{ The Arts Division } & \multicolumn{2}{|c|}{ The Science Division } & \multirow[b]{2}{*}{ Total } \\
\hline & Humanities & Business & Social Science & Engineering & Science & \\
\hline Past Experiences & 45 & 40 & 59 & 74 & 84 & 302 \\
\hline Prospects & 28 & 11 & 36 & 36 & 44 & 155 \\
\hline Total & 73 & 51 & 95 & 110 & 128 & 457 \\
\hline
\end{tabular}


A closer examination of these concordance lines and their surrounding texts also suggests that the concordances in the Science division tend to include more details than those in the Arts division. Such difference is likely to be caused by academic disciplines' different trainings in research design: compared with their peers in the Science divisions, students enrolled in the Arts division in China tend to have less opportunities to conduct independent research. Examples 1a and 1b below illustrate how the applicants in both divisions summarize their past research experiences. Although both examples are research intensive narratives by the applicants to establish their credentials in research skills, they achieve the same communicative purpose through two distinctive persuasive strategies: example 1a focuses on the applicants' education trainings and how these trainings have provided him/her with research skills and inspired further curiosities. By comparison, example 1b offers more details by discussing how's the applicant's specific technical skills and research expertise.

Example 1a. Extract from a SoP written for a master program in South-East Asian Studies

I've already spent 3 years in the study of teaching Chinese as a foreign language. [...] It has not only built me solid academic background, but also prepared me for the future China studies. Thanks to what I've learned through my undergraduate study, I have demonstrated proficiencies in RESEARCH and analytical skills. It was after attending RESEARCH seminars in my junior year that I began to set foot in the area of RESEARCH. Then the interest for RESEARCH was nurtured. [...] However, the RESEARCH of Chinese acquisition and pedagogy demands the combination of qualitative and quantitative methods to ensure the validity and reliability. Statistics for Business and Economics by David R. Anderson, Dennis J. Sweeney and Thomas A. Williams really helped me build the statistical frame for my RESEARCH when I started to learn statistics. [...]

Example 1b. Extract from a SoP written for a master program in Biomedical Engineering

Four years of professional study and practice fostered not only my independent learning and research abilities, but also my innovation and continuous probe in scientific RESEARCH. But there are still a lot of problems in reality that I am not able to solve with my limited knowledge. [...] Hence I hope to gain further study, master advanced knowledge and RESEARCH methods and engage in cutting-edge technologies to answer my questions. Through my professor's recommendation and my RESEARCH, I found that the MS program in Biomedical Engineering at X University fits me the most. The department of biomedical engineering possesses excellent faculty and professors along with leading RESEARCH fields. This program provides students flexible and comprehensive curriculum, in which the RESEARCH area of biomaterials about both living tissue and artificial materials used for implantation and to foster cell function as well as the RESEARCH on the selection of an appropriate material to place in the human body attract me a lot. In addition, this program stresses the development of students' RESEARCH abilities and creativities, which benefits students' career developments. [...] 
Table 5 summarizes the concordance lines of the lemma "China". The concordance lines here also consist of two major content types: they focus on either the applicants' Chinese linguistic and cultural backgrounds or China's academic, social and cultural issues. As found in the lexical frequency analysis, China/Chinese related expressions are frequently used by SoPs in the Arts division and the results in Table 6 further confirm this pattern: The China/Chinese related expressions in the Arts division often construct a sense of distinctiveness by suggesting: (1) how the applicants' Chinese linguistic and cultural backgrounds have equipped them with unique study/research insights, and (2) how certain academic, social and cultural issues in China have inspired the applicants to pursue further study/research.

Examples $2 \mathrm{a}$ and $2 \mathrm{~b}$ below illustrate both narrative strategies. Both strategies are particularly favored by the humanities corpus and the social science corpus, probably due to the two fields' close connections with culture-oriented epistemologies. Occasionally, such expressions construct China as a country inferior to the West in terms of its academic, social and cultural developments, as shown in Example 2c in which the applicant regards "escaping from China" as his/her primary motive of studying in Hong Kong.

Example 2a. Extract from a SoP written for a master program in applied linguistics

I have been exposed to various kinds of CHINESE culture since I was a child. At the age of five, I started to learn CHINESE brush calligraphy. I was attracted by CHINESE painting and made efforts to grasp it when I was 10 years old. During junior high, I began to read China Five Thousand-Years History and especially developed great interest in Chinese history. I was so mesmerized by CHINESE culture and the beauty of CHINESE characters in particular that I chose the major of Teaching CHINESE as a second language in English for my undergraduate study. [...]

Example 2b. Extract from a SoP written for a master program in communication studies

Back in CHINA, as the only undergraduate research assistant for a project on civil protest online, I began to pay attention to the issue of "massive Internet incidents", which involves one million or more visits by users and generates billions of online discussions. With the recent explosive growth of social media in CHINA, the Internet has further multiplied its importance as an alternative outlet for the CHINESE public's discontent whereas traditional mass media are largely silenced by state regulation. Noticeably, in the past a few months, CHINA has seen several spectacular environment- related massive Internet incidents. [...] Given CHINA's unique information environment characterized by stringent regulation on mass media, the comparatively "freer" Internet becomes an ideal incubator to nurture

Table 5 Concordance lines of the lemma "China" in the SoP corpora

\begin{tabular}{lllllllll}
\hline & \multicolumn{3}{l}{ The Arts Division } & & \multicolumn{2}{l}{ The Science Division } & \\
\cline { 2 - 3 } & Humanities & Business & Social Science & & Engineering & Science & Total \\
\hline Background & 130 & 27 & 29 & & 12 & 25 & 223 \\
Socio-cultural issues & 77 & 32 & 96 & & 18 & 16 & 239 \\
Total & 207 & 59 & 125 & 30 & 41 & 462 \\
\hline
\end{tabular}


Table 6 Functional Moves of the SoP corpora

\begin{tabular}{|c|c|c|c|c|c|}
\hline & \multicolumn{3}{|c|}{ The Arts Division } & \multicolumn{2}{|c|}{ The Science Division } \\
\hline & Arts & Business & Social Science & Engineering & Science \\
\hline Move 1: Introduction (106/120) & 17 & 18 & 20 & 16 & 20 \\
\hline Step 1-A: Generalization/Attention catcher & 8 & 9 & 5 & 10 & 8 \\
\hline Step 1-B: Background & 12 & 8 & 10 & 10 & 13 \\
\hline Step 1-C: Goals or decisions to applying & 6 & 10 & 11 & 10 & 9 \\
\hline Move 2: Establishing credential (120/120) & 20 & 20 & 20 & 20 & 20 \\
\hline Step 2-A: Education background & 20 & 17 & 15 & 17 & 18 \\
\hline Step 2-B: Research experience & 9 & 11 & 11 & 17 & 20 \\
\hline Step 2-C: Work experience & 12 & 14 & 10 & 9 & 6 \\
\hline Step 2-D: Personal attributes & 5 & 7 & 6 & 10 & 1 \\
\hline Step 2-E: Other experience & 13 & 17 & 13 & 8 & 6 \\
\hline Move 3: Reasons for applying $(117 / 120)$ & 20 & 20 & 20 & 19 & 18 \\
\hline Step 3-A: Gap in applicant background & 9 & 9 & 6 & 7 & 3 \\
\hline Step 3-B: Positive gains & 11 & 16 & 9 & 10 & 4 \\
\hline Step 3-C: Program/university attributes & 17 & 12 & 17 & 16 & 17 \\
\hline Step 3-D: Disciplinary and research reasons & 9 & 7 & 11 & 13 & 15 \\
\hline Move 4: Conclusion (105/120) & 17 & 18 & 19 & 19 & 16 \\
\hline Step 4-A: Goals/predictions of future & 7 & 10 & 11 & 10 & 9 \\
\hline Step 4-B: Self-evaluation & 8 & 9 & 7 & 13 & 6 \\
\hline Step 4-C: Final appeal & 13 & 9 & 11 & 5 & 10 \\
\hline
\end{tabular}

public concerns for environmental justice, an educational tool for raising awareness of public health risks, and a platform for organizing large-scale civic interventions.

Example 2c. Extract from a SoP written for a master program in journalism studies

To be frank, I have difficulty in adapting to mainland CHINA's education system which neglects independent thinking, imagination and stress tolerance. With $\mathrm{X}$ University's teaching culture of critical thinking and intellectual confrontation, I'm looking forward to being with students and teachers with various culture backgrounds and social experiences, enjoying pleasure brought by thoughts collision. [...] As the international financial and trade center and CHINESE circle core city, Hong Kong, in which I anticipate to broaden my horizon, is a huge attraction to me. Also, Hong Kong is a developed information society with freedom of press and freedom of speech which mainland CHINA does not have. What's more, it is home to numerous world-renowned media organizations, providing me with broad development platform of media industry in the future.

\section{Rhetorical move structures}

Table 6 shows the frequencies of the functional moves and their associated steps across the five SoP corpora. Although most coded SoPs include the four general moves "Introduction" (IN), "Establish Credentials" (EC), "Reasons for Applying" (RA) and "Conclusion" (CO), there are a couple of inter-corpus differences in the frequencies of each move's associated steps. Among the four general moves, EC and RA are the most well-established, with all 
SoP samples including the EC move and only three of them missing the RA move. The other two moves, IN and CO, also appear in most SoP samples. Among the 120 SoP samples, only 14 lack the IN move and 15 lack the CO move. Thus, the results in Table 6 provide empirical support for the prototypical IERC (IN-EC-RA-CO) move structure proposed by previous research (Chiu, 2016; Ding, 2007; Samraj \& Monk, 2008).

In terms of functional steps, the corpora are similar with each other in each move's most frequent step. For example, in the EC move, "education" is the most frequent step across disciplines and this pattern is also shown in the "program/university attributes" step of the RA move. Meanwhile, no clear pattern is found in the most frequent steps of the IN and CO moves, which indicates that the SoP writers have different opinions on what should be addressed in these moves. Inter-corpus variations also emerge in other steps, especially in those of the EC and RA moves. In the EC move, the step "research" appears more frequently in the Science division than in the Arts division whereas the steps "work experience" and "other experience" are more frequently found in the Arts division. Similarly, in the RA move, the step "disciplinary/research reasons" was frequently adopted by corpora in the Sciences division, but not in the Arts Division. By comparison, the step "positive gains" tends to be more preferred by the Arts division than the Science division.

When coding the SoP samples, one convenient function offered by NVivo 10 is that it is able to display the length ratios of moves and steps within each coded sample. For instance, a coded SoP can be shown as comprised by $5.91 \%$ IN, $59.49 \%$ EC, $24.88 \%$ RA, and $10.58 \% \mathrm{CO}$. These ratios are indicative of the relative attention paid to each move during the SoP's writing process. Following the results in Table 6, the average length ratios of each move across the corpora are calculated and the results are shown in Table 7. As expected, the high average ratios of the EC and RA moves in Table 7 confirms both as the most important moves of the SoP genre. Moreover, both corpora in the Science division have higher averages than those in the Arts division and this distinction is further supported by the one-way ANOVA test ${ }^{2}(p=0.014)$. Another statistical significance is found in the RA move $(p=0.016)$, which is likely to be caused by the relatively low average ratios of the business corpus and the science corpus.

Given the centrally of the EC and RA moves in SoP writing, there may be potential disciplinary variations in their respective functional steps. Applicants may choose to highlight different aspects of themselves in both moves due to different disciplinary trainings. As shown in Table 5, the most common functional steps in the EC move are "research experience", "work experience" and "other experience" while in the RA move they are "positive gains" and "disciplinary/research reasons". I calculated the length

Table 7 Average move length ratios of the SoP corpora

\begin{tabular}{|c|c|c|c|c|c|c|c|}
\hline & \multicolumn{3}{|c|}{ The Arts Division } & \multicolumn{3}{|c|}{ The Science Division } & \multirow[b]{2}{*}{$p$ value } \\
\hline & Humanities & Business & Social Science & Engineering & Science & Total & \\
\hline 1. Introduction & $10.51 \%(17)$ & $9.53 \%(18)$ & $10.47 \%(20)$ & $9.72 \%(16)$ & $11.07 \%(20)$ & $10.29 \%(107)$ & 0.942 \\
\hline $\begin{array}{l}\text { 2. Establishing } \\
\text { credential }\end{array}$ & $53.93 \%(20)$ & $57.48 \%(20)$ & $49.62 \%(20)$ & $59.32 \%(20)$ & $65.57 \%(20)$ & $57.18 \%(120)$ & 0.014 \\
\hline $\begin{array}{l}\text { 3. Reasons for } \\
\text { applying }\end{array}$ & $29.02 \%(20)$ & $23.83 \%(20)$ & $32.50 \%(20)$ & $27.61 \%(19)$ & $18.45 \%(18)$ & $26.43 \%(117)$ & 0.046 \\
\hline 4. Conclusion & $7.26 \%(17)$ & $8.44 \%(18)$ & $6.87 \%(19)$ & $6.75 \%(19)$ & $7.91 \%(16)$ & $7.42 \%(105)$ & 0.822 \\
\hline
\end{tabular}

Note: The figure $\mathrm{Y}$ in $\mathrm{X} \%(\mathrm{Y})$ refers to how many samples of each corpus contain the specific move 
ratios of these functional steps in each SoP and then compared the five disciplines' results with each other. As shown in Table 8, the average length ratios of the "ECresearch experience" step follows the EC move's pattern in Table 7, with the Science division having higher average ratios than the Arts division. However, this pattern is reversed in the "EC-other experience" and "RA-positive gains" steps, with the Arts division having the higher average ratios. The social science corpus stands out among others in its high average ratio in the "RA-disciplinary/research reasons" step. A closer look at this step in the social science corpus reveals that many discussions made here are linking the applicants' proposed study/research fields with broader socio-cultural issues in China (Example 2b), which echoes the social science corpus' pattern in Table 8. The one-way ANOVA test identifies statistical significance in the "EC-research experience" step $(p=0.029)$ and the "RA-disciplinary/research reasons" step $(p=0.016)$.

\section{Discussion and conclusion}

This study has examined the SoP genre's potential disciplinary variations in lexicogrammatical and rhetorical features. Following a corpus-driven, bottom-up analytical procedure, the study has revealed a somewhat surprising picture, finding that there are noticeable differences between SoPs written for the Arts division and those written for the Science division. Thus, while this study has provided further empirical evidence to define the SoP as an academic self-promotional genre, it has also offered several valuable insights of the SoP genre's disciplinary variations in textual regularity.

To be specific, when discussing research experiences and prospects, SoPs written for the Science division tend to include much more details than those written for the Arts division, which is shown in the concordance lines of the lemmas "research" and in the two Science corpora's high average length of the RA move and its associated "research experience" step. One possible explanation for these results is the difference in academic training between the two divisions within China's post-secondary education system: students in the Science division tend to receiving more formal instruction in research methodology than their peers in the Arts division.

The concordance analysis also identifies how the Chinese EAL writers, especially those in social science majors, using the discussion of China's academic, social and cultural issues as a persuasive strategy when explaining their reasons for applying. However,

Table 8 Average step length ratios of the SoP corpora

\begin{tabular}{|c|c|c|c|c|c|c|c|}
\hline & \multicolumn{3}{|c|}{ The Arts Division } & \multicolumn{3}{|c|}{ The Science Division } & \multirow[b]{2}{*}{$p$ value } \\
\hline & Arts & Business & $\begin{array}{l}\text { Social } \\
\text { Science }\end{array}$ & Engineering & Science & Total & \\
\hline $\begin{array}{l}\text { Step 2-B: Research } \\
\text { experience }\end{array}$ & $28.35 \%(9)$ & $17.21 \%(11)$ & $25.86 \%(11)$ & $32.01 \%(17)$ & $36.30 \%(20)$ & $29.40 \%(68)$ & 0.029 \\
\hline $\begin{array}{l}\text { Step 2-C: Work } \\
\text { experience }\end{array}$ & $16.05 \%(12)$ & $21.04 \%(14)$ & $19.37 \%(10)$ & $22.03 \%(9)$ & $14.86 \%(6)$ & $18.99 \%(51)$ & 0.652 \\
\hline $\begin{array}{l}\text { Step 2-E: Other } \\
\text { experience }\end{array}$ & $22.68 \%(13)$ & $20.51 \%(17)$ & $24.13 \%(13)$ & $19.43 \%(8)$ & $18.05 \%(6)$ & $20.55 \%(57)$ & 0.884 \\
\hline $\begin{array}{l}\text { Step 3-B: Positive } \\
\text { gains }\end{array}$ & $15.04 \%(11)$ & $11.63 \%(16)$ & $15.64 \%(9)$ & $10.73 \%(10)$ & $6.92 \%(4)$ & $12.54 \%(50)$ & 0.148 \\
\hline $\begin{array}{l}\text { Step 3-D: Disciplinary } \\
\text { and research reasons }\end{array}$ & $16.15 \%(9)$ & $14.86 \%(7)$ & $28.01 \%(11)$ & $17.17 \%(13)$ & $11.19 \%(15)$ & $17.25 \%(55)$ & 0.016 \\
\hline
\end{tabular}

Note: The figure $\mathrm{Y}$ in $\mathrm{X} \%(\mathrm{Y})$ refers to how many samples of each corpus contain the specific step 
privileging Western cultures and education resources may not be effective. Although it is understandable that many SoP writers here address the inadequacy of studying in China thereby justifying their desires of studying abroad, in essence such negative expressions imply the "self-critique" strategy in Chinese rhetoric and it may not be an appropriate rhetorical choice for self-promotional writing in the tradition of Anglo-American culture. For graduate programs (e.g. Asian studies and sociology) requiring in-depth thinking into socio-political issues, the one-sided interpretation on Chinese society may leave graduate admission committees with negative impressions. To a large extent, this rhetorical strategy reflects the Chinese EAL writers' struggles in entering the Western academic community. While most EAL writers in the present study are able to overcome the language barrier, they still need to deal with unfamiliar academic conventions (especially in the Arts division where research tends to be contextual) and cultural preferences. As such, the present study also invites us to how cultural factors play in the complex genrediscipline interactions (Hyland, 2012).

Taken together, the above findings offer meaningful implications for future research in promotional genres and potential pedagogical developments in EAL writing instruction. Methodologically, this study differs from previous research on the SoP genre in that it takes a quantitative, bottom-up approach. Although corpus-driven genre analysis is still in its early development and its accuracy at the discursive level can be unsatisfactory, its ability to handle large-size data remains extremely helpful in improving research validity and detecting less-obvious textual patterns. Although many findings are somewhat expected, the quantitative analyses are still insightful in that they improve our understandings in how self-promotion, the SoP's overarching communicative purpose, are achieved at micro levels. Given the increasing availability of online language corpora and the advancement of text compilation technologies, corpus-driven methods would make more contributions to genre research in the near future.

Pedagogically, the study sheds light upon the potential benefits of using the SoP genre in EAL writing instruction. Although the EAL writers in the present study have demonstrated their awareness of the SoP's general genre features without formal SoP writing instruction, we should keep in mind that the study's data selection process excluded most "problematic" SoPs. The SoP's semi-occluded nature remains a great challenge for prospective writers. Inappropriate SoPs can hurt one's graduate application and thus SoP-related instruction can benefit EAL students in their graduate application processes and even in their long-term academic development. In addition, SoP-related instruction can even benefit students without graduate study plans since rhetorical strategies in self-promotion are also needed in professional contexts. In this respect, we may consider the SoP as a "bridging" genre since many discursive strategies learnt from it can be transferred to other academic and professional genres.

Admittedly, the study is limited by its exclusive focus on Chinese EAL writers and the disciplinary variations of the SoP genre. Thus, the findings may not be generalized to other research scenarios. As a less-studied genre, many aspects of the SoP are yet to be addressed and I hope that the present study would serve as a call for future research into this complex student genre. 


\title{
Endnotes
}

${ }^{1}$ The lemma frequencies in the concordance analysis differ from the lexical frequency results since a lemma's different forms are calculated together: "research/researches/ researching/researched" and "China/Chinese". In addition, to improve accuracy, concordance lines with the lemmas "research" and "Chinese/China" being used as parts of proper nouns are also excluded (e.g. CHINESE academy of science, CHINA central television, electronic engineering RESEARCH group, etc.).

${ }^{2}$ For SoP samples missing certain moves (e.g. IN and $\mathrm{CO}$ ), their length ratios are treated as "missing" during the statistical analysis.

\begin{abstract}
Acknowledgements
I would like to thank Dr. Li-Shih Huang and Dr. Hossein Nassaji from University of Victoria for their constructive suggestions on earlier drafts of this article. I would also thank Vanier Canada Graduate Scholarship for its support of my research at Simon Fraser University, and the editors and reviewers from Functional Linguistics for their insightful comments throughout the peer review process.
\end{abstract}

\section{Competing interests}

The author declares that he has no competing interests.

\section{Ethics approval and consent to participate}

Data collection of this paper has followed the standards and guidelines of the research ethics review board at the author's home institution.

Received: 23 December 2016 Accepted: 15 February 2017

Published online: 23 February 2017

\section{References}

Anthony, L. 2011. AntConc (Version 3.2.1) [Computer software]. Retrieved from http://www.laurenceanthony.net/. Accessed 1 Nov 2016

Bhatia, V.K. 1993. Analyzing genre: Language use in professional settings. London: Longman.

Brown, R.M. 2004. Self-composed: Rhetoric in psychology personal statements. Written Communication 21(3): 242-260. doi:10.1177/0741088304264338.

Chen, S., and H. Nassaji. 2015. Politeness strategies in personal statements: A comparative analysis between Native and Non-Native English writers, 62-81.. CASDW (Canadian Association for the Study of Discourse and Writing) annual conference proceedings 2014.

Chiu, Y.T. 2015. Personal statement in PhD applications: Gatekeepers' evaluative perspectives. Journal of English for Academic Purposes 17: 63-73. doi:10.1016/j.jeap.2015.02.002.

Chiu, Y.T. 2016. 'Singing your tune': Genre structure and writer identity in personal statements for doctoral applications. Journal of English for Academic Purposes 21: 48-59. doi:10.1016/j.jeap.2015.11.001.

Coe, R.M. 2002. The new rhetoric of genre: writing political briefs. In Genre in the classroom, ed. A.M. Johns, 195-205. Mahwah: Erlbaum.

Ding, H. 2007. Genre analysis of personal statements: Analysis of moves in application essays to medical and dental schools. English for Specific Purposes 26(3): 368-392. doi:10.1016/j.esp.2006.09.004.

Dubb, C. 2011. [Re]presenting the self in graduate school application essays: Research into the process behind high-stakes writing (Doctoral dissertation).. Retrieved from University of Pennsylvania Scholarly Commons (AAl3492300).

Hyland, K. 2012. Disciplinary identities: Individuality and community in academic discourse. Cambridge: Cambridge University Press.

Hyon, S. 1996. Genre in three traditions: Implications for ESL. TESOL Quarterly 30(4): 693-722.

Samraj, B., and L. Monk. 2008. The statement of purpose in graduate program applications: Genre structure and disciplinary variation. English for Specific Purposes 27(2): 193-211. doi:10.1016/j.esp.2007.07.001.

Swales, J.M. 1990. Genre analysis: English in academic and research settings. Cambridge: Cambridge University Press.

Swales, J.M. 1996. Occluded genres in the academy: The case of the submission letter. In Academic writing: Intercultural and textual issues, ed. E. Ventola and A. Mauranen, 45-58. Amsterdam: John Benjamins.

Swales, J. 2004. Research genres: Explorations and applications. New York: Cambridge University Press. 